\title{
Oxytocin, vasopressin and nitric oxide levels in cerebrospinal fluid in women with migraine and fibromyalgia (Abstract)
}

Níveis de ocitocina, vasopressina e óxido nítrico no líquido cefalorraquidiano em mulheres com enxaqueca e fibromialgia (Resumo)

\section{Louana Cassiano da Silva Lima}

Thesis (Doctorate in Neurosciences). Postgraduation in Neuropsychiatry and Behavioral Sciences. Federal University of Pernambuco, Recife, Brazil. 2017. 86 f. Supervisor: Prof. Dr. Marcelo Moraes Valença.

$\bigotimes_{\text {louana_cs@hotmail.com }}$

Keywords:

Migraine disorders,

Fibromyalgia

Cerebrospinal fluid

Nitric oxide

Oxytocin

Vasopressins

Depression, Anxiety

Stress

Psychological

\section{Introduction}

Migraine and fibromyalgia share similar pathophysiological mechanisms. Alterations in the nervous system indicate the involvement of brain function in fibromyalgia. Significant changes in the plasma concentrations of oxytocin, vasopressin, and nitric oxide in migraineurs have been reported.

\section{Objective}

To analyze the concentrations of oxytocin, vasopressin, and nitric oxide in the cerebrospinal fluid (CSF) of women with migraine and fibromyalgia and correlate the levels with headache intensity, headache impact, symptoms of depression and anxiety, stress levels, sleep quality, and fatigue.

\section{Method}

This is an observational cross-sectional study performed at the Hospital das Clínicas of the Federal University of Pernambuco. For this, 246 women were interviewed. Headache characteristics in the last three months were reported and classified according to ICHD-3ß. American College of Rheumatology criteria (2010) were used to classify fibromyalgia. All women respond to questionnaires regarding depressive and anxious symptomatology, fatigue severity, perception of stress, quality of sleep, and headache impact. CSF sample was collected from 33 women and analyzed by the radioimmunoassay technique.

\section{Results}

There was no relationship between oxytocin, vasopressin, and nitric oxide levels in the CSF in migraine and fibromyalgia patients. Relationships with headache intensity, headache impact test, depressive and anxious symptoms, fatigue, stress, and sleep quality were not established. In women with migraine, the presence of fibromyalgia syndrome increases the pain intensity of headache (migraine $7.95 \pm 0.12$ vs. migraine + fibromyalgia $8.78 \pm 0.21, p<0.05$ ), the impact of headache (migraine $63.88 \pm 0.67$ vs. migraine + fibromyalgia $67.73 \pm 1.25, p<0.05)$, depressive symptomatology (migraine $6.45 \pm 0.38$ vs. migraine + fibromyalgia $8.9 \pm 0.38, p<0.05$ ) and the perceived stress (migraine $26.6 \pm 0.63$ vs. migraine + fibromyalgia $30.73 \pm 0.99, p<0.05$ )

\section{Conclusion}

No correlation was found between oxytocin, vasopressin, and nitric oxide levels in women with migraine and fibromyalgia. 